\title{
THE CLASSIFICATION AND PROGNOSIS OF NEPHRITIS AND ALLIED RENAL DISEASES
}

\author{
By. M. D. Milne, M.D., Ch.B., M.R.C.P. \\ Physician and Lecturer, Postgraduate Medical School, London
}

A satisfactory classification of nephritis which will correlate with pathological findings and will permit an accurate prognosis, has proved a matter of great difficulty. It is a constant source of worry to the postgraduate student who fears that the particular classification and nomenclature he has learned and adopted may be anathema to examiners for higher degrees and diplomas who may happen to belong to a rival school of thought. The main difficulty is that the clinician observes manifestations of abnormal renal function, whilst the morbid anatomist is concerned with structural abnormalities which are frequently the terminal results of longstanding renal disease.

Different diseases may produce an almost identical clinical and functional abnormality and the same pathological process may vary widely in its effects on renal function and in the rapidity of its progression or resolution. Correlation of clinical and pathological data will probably be facilitated in the future by greater use of renal biopsy techniques (Kark and Muehrake, I954; Iversen and Brun, I95I), but it is doubtful whether this method will ever prove as popular and useful as aspiration biopsy of the liver in the assessment of hepatic disease. Diagnosis and classification of nephritis must, in the main, be dependent on an accurate clinical history to give an indication of past events and on tests of renal function to define the existing state. Modern clearance methods have previously been regarded as research procedures, but are now becoming used as routine methods in the difficult case. Their significance and average normal values are given in Table $\mathbf{~}$. In most cases, however, more simple tests suffice, including the urea clearance which is roughly proportional to, but always lower than, the clearance of inulin, and the determination of maximal concentrating power to give an indication of distal tubular function. In addition, it is essential to examine the spun deposit for red cells, leucocytes and casts, and to determine the degree of proteinuria expressed as the amount in grams lost each day.
All authorities now agree that primary nephritis can be divided into the two main categories of glomerulo-nephritis and pyelo- $\dot{\omega}$ nephritis. Glomerulo-nephritis, as its name sug- gests, primarily affects the glomeruli, and at its onset is diffuse and uniform throughout both 0 kidneys. At some stage of the disease proteinuria 을 is usually of severe degree, casts are plentiful andthere is in most cases an oedematous stage. Pyelo- $\square$ nephritis primarily affects the pelvis, collecting $\mathscr{\Phi}_{\overparen{\infty}}$ and distal tubules, although it may involve the $\bar{乛}$ glomeruli later. It is patchy in distribution and may be unilateral. Proteinuria is never of severe degree, almost always amounting to less than $2 \mathrm{~g}$. each day and completely absent in some cases. (Raaschou, 1945). Casts are scanty and oedenta never occurs unless it is secondary to hypertensive cardiac failure. Pyuria and bacteriuria are present in the acute stage and during acute exacerbations, but may be completely absent for long periods $\stackrel{\square}{\Omega}$ during the chronic stage.

\section{Acute Glomerulo-Nephritis}

The course and prognosis of this disease have been well described by Rudebeck (1946) and by Ellis (1942), who terms it 'Type I nephritis.' It 3 . commonly commences from one to three weeks:after a streptococcal infection, usually acute tonsillitis. It is considered to be due to an abnormal $\delta$ immune response, since the anti-streptolysin titre is usually found to be high (Lyttle et al., 1938) and 0 serum complement to be low (Lange et al., r $95^{\mathrm{I}}$; Kellett, 1952). A similar condition may be pro-o duced in animals by injection of anti-serum prepared from homologous kidney (Masugi, r 934). O Rammelkamp et al. (1952) have emphasized the $N$ differences in the response from that seen in acute $\mathrm{CW}_{\mathrm{S}}$ rheumatism which may similarly follow strepto- $\sigma$ coccal infections. Glomerulo-nephritis either occurs sporadically or in large (Brown, 19r6) or $\frac{0}{\Phi}$ small (Kempe et al., 1951) epidemic waves following infection with streptococci showing ' nephrito- 0 genic' tendencies, most commonly a Type 120 
TABLE I

Clearance Methods of Assessment of Renal Function

\begin{tabular}{|c|c|c|c|c|}
\hline \multirow{2}{*}{ Clearance } & \multirow{2}{*}{$\begin{array}{l}\text { Average Value } \\
\text { corrected to } \\
\text { surface area } \\
\text { of } 1.73 \text { sq.m. }\end{array}$} & \multirow{2}{*}{ Function Measured } & \multicolumn{2}{|c|}{ Effect of Nephritis on clearance } \\
\hline & & & $\begin{array}{l}\text { Glomerulo- } \\
\text { nephritis }\end{array}$ & $\begin{array}{c}\text { Pyelo- } \\
\text { nephritis }\end{array}$ \\
\hline Inulin clearance & $123 \mathrm{ml} . / \mathrm{min}$ & Glomerular filtration rate & - (early) & - (late) \\
\hline $\begin{array}{l}\text { Para-aminohippurate (PAH) } \\
\text { clearance }\end{array}$ & $634 \mathrm{ml} . / \mathrm{min}$. & Renal plasma flow & - or $\mathbf{N}$ & - \\
\hline $\begin{array}{l}\text { Inulin clearance: PAH clearance. } \\
\text { (Filtration fraction) }\end{array}$ & 19.4 per cent. & $\begin{array}{l}\text { Fraction of plasma filtered } \\
\text { through glomeruli }\end{array}$ & - & $\mathrm{N}$ or + \\
\hline$\overline{\left.\text { Extraction ratio PAH (E } \mathrm{E}_{\mathrm{PAH}}\right)}$ & 92 per cent. & $\begin{array}{l}\text { Fraction of plasma perfus- } \\
\text { ing functional renal tissue }\end{array}$ & - & - \\
\hline $\begin{array}{l}\text { Tubular maximal resorptive } \\
\text { capacity (TmPAH) }\end{array}$ & $78.9 \mathrm{mg} . / \mathrm{min}$ & Proximal tubular function & $\begin{array}{l}N(\text { early) } \\
\text { - (late) }\end{array}$ & - \\
\hline Inulin clearance: $\mathrm{Tm}_{\mathrm{PAH}}$ & I.55 ml. $/ \mathrm{mg}$. & $\begin{array}{l}\text { Ratio of glomerular to } \\
\text { tubular function }\end{array}$ & 一 & + \\
\hline
\end{tabular}

Figures quoted are mean values taken from Smith, H. W. (195I), 'The Kidney: Structure and Function in Health and Disease.' New York.

organism (Rammelkamp and Weaver, 1953). Rheumatic fever occurs sporadically after infections with any group A streptococcus and tends to relapse with later infections. A second attack of acute glomerulo-nephritis is very rare provided a full recovery from the first attack takes place.

The classical symptoms and signs are haematuria, oedema of slight or moderate degree, oliguria and hypertension. There is considerable proteinuria and the urine is usually of high specific gravity and contains very little sodium chloride. Hospital physicians, other than physicians in fever hospitals, do not see sub-clinical cases, but there is no doubt that these occur. If cases of scarlet fever are followed after apparent recovery a proportion will show sub-clinical nephritis recognizable only by careful examination of the urine (McCrae, 1913; Weinstein et al., 1950). Similarly, during epidemics of acute nephritis (Kempe et al., 195I) sub-clinical cases are to be found by urinary examination of cases of tonsillitis who never show overt clinical nephritis. Long-term follow-up data on such sub-clinical cases is insufficient for us to be certain whether the proportion going on to chronic nephritis is similar to that following overt acute nephritis, but there is indirect evidence that it may be. Rudebeck (1946) has shown that, apart from death in the acute stage of the disease, the prognosis as to complete recovery depends only on the age of the patient. Over 90 per cent. of cases under 30 , but less than 50 per cent. over 50 , recover completely. The prognosis does not appear to be influenced by the severity of the albuminuria, haematuria or oedema. Severe hypertension is an adverse feature, but the highest blood pressures are seen in the more elderly cases. Acute nephritis results in an acute increment of blood pressure above the basal level which is known to rise with increasing age (Hamilton et al., 1954). It seems likely, therefore, that the prognosis in sub-clinical cases of acute nephritis will be uninfluenced by the mildness of the disease, and that a proportion will not resolve completely and account for some examples of chronic glomerulonephritis without a previous history of acute attack.

Ellis (1942) showed that in overt cases there were four possible alternatives with regard to the outcome of the disease.

(a) The great majority (82 per cent. of Ellis's cases) recovered completely, as shown by disappearance of hypertension, haematuria, oedema and, finally, albuminuria.

(b) A small proportion ( 4 per cent.) died in the acute stage. Possible causes of death are uncontrolled streptococcal infection, cardiac failure which is commoner in the elderly patient, repeated convulsions and anuria or severe oliguria. The last possibility is an especially serious complication since the prognosis is more grave than in oliguria or anuria due to acute tubular necrosis. The anuria occurring as a complication of acute glomerulo-nephritis is more often absolute and tends to be more prolonged (Swann and Merrill, 1953), the anuric or oliguric phase sometimes lasting longer than four weeks before diuresis eventually supervenes.

(c) Some cases (4 per cent.) never lost the oedema or haematuria. Proteinuria increased 
steadily in amount and the patients passed into a nephrotic stage before dying of uraemia within a year of the onset of the illness.

(d) The remainder (ro per cent.) gradually lost their oedema and haematuria and often the hypertension, but retained their proteinuria. They became symptomatically recovered, often for many years. Throughout this period, however, there was an insidious and progressive failure of renal function until hypertension recurred and the patients died of uraemia many years after the acute attack.

\section{The Nephrotic Syndrome}

There is still considerable controversy with regard to the terminology and classification of cases of the nephrotic syndrome. It is a condition characterized by massive oedema often associated with serous effusions, severe albuminuria, hypoalbuminaemia and hypercholesterolaemia. Some authorities exclude cases complicated by haematuria, hypertension and retention of non-protein nitrogen. This seems to be an artificial distinction since cases which originally do not show any of these features may develop them as the condition progresses. In addition, it is very difficult to draw an exact dividing line between the normal and abnormal in any of these three complications. In particular, definition of a normal blood pressure can only be based on statistical data (Hamilton et al., I954) and the level of blood urea is dependent on the amount of protein ingested as well as on renal function. Most cases show some degree of microscopic haematuria from the onset (Galan, 1949). It is considered preferable therefore to refer to such cases as examples of the nephrotic syndrome complicated by hypertension, haematuria or uraemia according to the abnormalities found.

The basic functional disorder is an increased permeability of the glomeruli to the plasma proteins (Chinard et al., I954), particularly to the low molecular weight fractions, e.g. albumin and $\alpha$ globulin (Squire, 1953). There is no evidence that plasma proteins in the nephrotic syndrome are qualitatively abnormal. Both plasma and urinary albumin have been shown to be of normal composition by immunological methods (Gitlin and Janeway, I952). Although the correlation is far from absolute, there is in general a parallel between the amount of urinary protein loss, the lowering of plasma albumin and the magnitude of the oedema (Squire, 1953). Oedema is liable to develop in the adult patient at levels of urinary protein loss of between 5 and ro g. each day and is usually present if the loss is higher than this.

Any condition which can so alter glomerular function that there is prolonged excessive urinary protein loss can therefore cause the nephrotic syndrome. Less severe manifestations of the same $\stackrel{\mathbb{Q}}{\stackrel{\infty}{\alpha}}$ disorder may result in smaller urinary protein loss $c$. and oedema will then not occur. Theoretically $\vec{F}$ there is no fundamental difference between these two types of renal abnormality, but to the patient? and the clinician the practical difference of the presence or absence of oedema is all important and $\frac{0}{\sigma}$ may determine whether the renal disorder is almost symptomless or completely incapacitating. ఉ Protein deficiency and oedema secondary to $-\overrightarrow{0}$ urinary loss of abnormal proteins should not be classed as examples of the syndrome. For example, $\vec{\omega}$ a patient was recently seen with gross anasarca ando with a constant proteinuria of $15 \mathrm{~g}$. each day There was severe hypoalbuminaemia, plasma. albumin being $2.0 \mathrm{~g}$./100 $\mathrm{ml}$. More careful urine testing showed that most of the urinary proteince was Bence-Jones protein and this was confirmed. by electrophoresis, almost all the protein being a? $\gamma$-globulin with only a small quantity of albumin. Although the low plasma albumin was almost? certainly secondary to the severe urinary protein loss this case did not show the fundamental ${ }_{\mathbb{\Phi}}$ abnormality of the nephrotic syndrome, i.e. in- $\Phi$ creased glomerular permeability to albumiar. 3 Bence-Jones protein is of small molecular weigf $t \frac{\Phi}{-}$ and is filtered through normal glomeruli.

The causes of the nephrotic syndrome can classified as follows:

(a) Cases resulting from renal complications of various systemic diseases, particularly diabetes mellitus, amyloidosis, disseminated lupus ery-음 thematosus and syphilis. In this country diabetic glomerulo-sclerosis or the Kimmelstiel-Wilson syndrome (1936) is the commonest cause of the $\overrightarrow{\overrightarrow{0}}$ nephrotic syndrome in adults. It has become 3 more common in recent years due to the fact that diabetics are kept alive for many years by insulin? and to the increased incidence of diabetes in obese음 elderly subjects in an ageing population. The prognosis is poor, there being a steady progression $\frac{5}{3}$ to terminal uraemia. Renal amyloidosis is usually. of the secondary variety but occasionally primary amyloidosis may involve the kidney to a significant extent (Thingstad, 195 I Reimann et al., 1954). 은

Amyloidosis secondary to chronic sepsis and un- $\rightarrow$ controlled tuberculosis is now becoming less common and the chief cause of this condition in many hospital series is rheumatoid arthritis. It should be suspected in any case of rheumatoid 0 arthritis showing albuminuria. In many cases the proteinuria is slight and the case then shows a slow? progression to renal failure rather than theo nephrotic syndrome. The prognosis is poor unless $\Phi$ the primary disease can be radically cured.? Similarly, although renal involvement in cases of ${ }^{7}$ disseminated lupus erythematosus is not un- $\frac{\text { Pे }}{\mathbb{D}}$ 


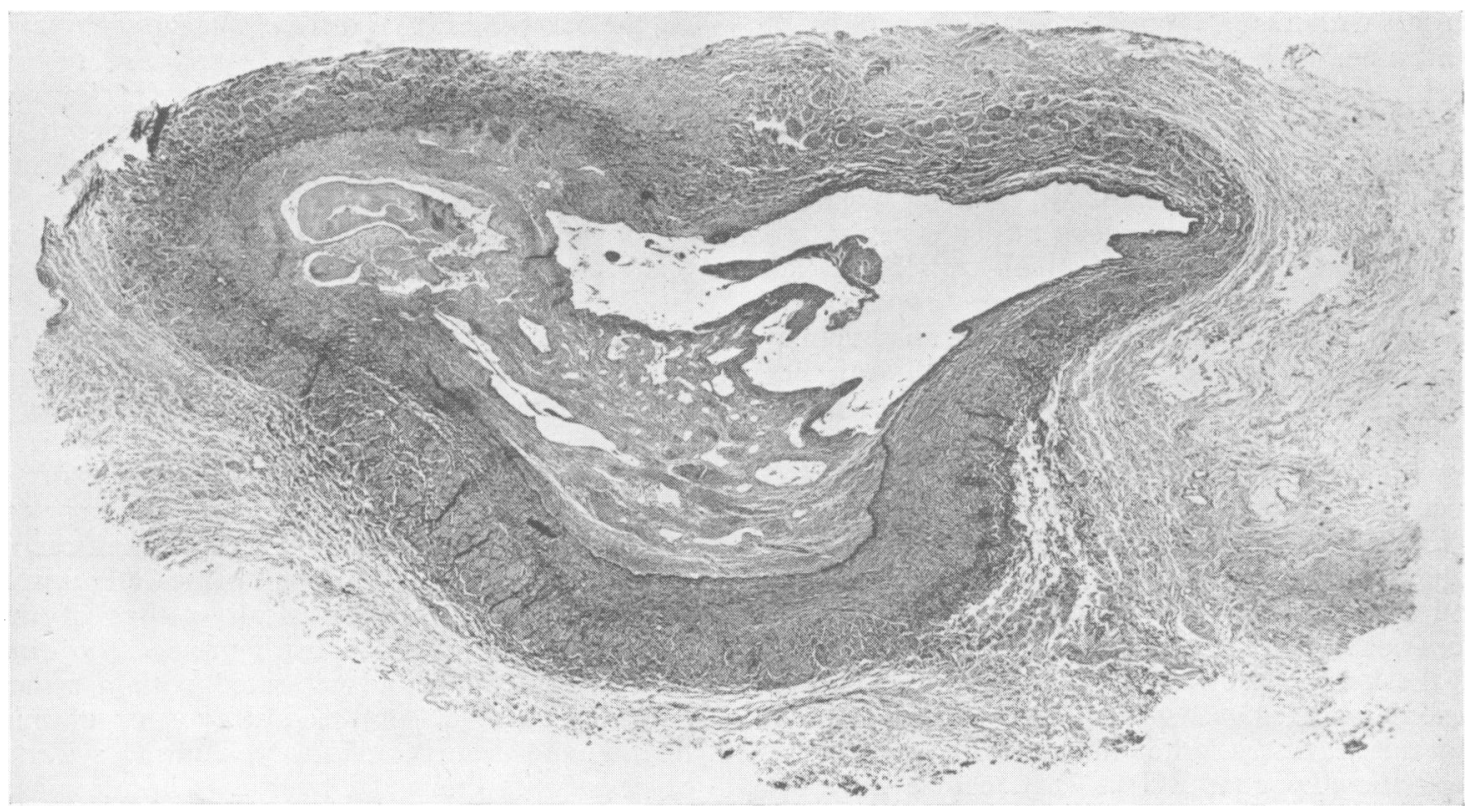

FIG. I.-Section through main tributary of renal vein in a case of the nephrotic syndrome. There is organizing thrombus becoming recanalized. This thrombus involved all the smaller tributaries of the renal veins but did not extend into the main renal vein trunks. $\times 17$.

common, the nephrotic syndrome occurs in only a proportion (Stickney and Keith, I940; Daugherty and Baggenstoss, I950). The prognosis is much more grave if there is evidence of renal involvement. Whilst most of the manifestations of this disease respond favourably to $\mathrm{ACTH}$ or cortisone, the renal complications are much more resistant to treatment. Syphilis is now rarely complicated by the nephrotic syndrome, presumably because of efficient means of therapy. The condition used to be seen in the secondary stage and usually responded well to anti-syphilitic therapy (Munk, 1913).

(b) As a result of drug toxicity. The nephrotic syndrome has been described after trimethadione used in the treatment of petit mal (Barnett et al., I948; White, 1949), gold salts (Vallery-Radot et al., 1942), inorganic mercury (Wilson et al., 1952) and after poison oak dermatitis (Rytand, I948). Although there is little doubt from the clinical descriptions of the cases that all these agents can cause the syndrome, the case due to trimethadione described by Barnett et al. (1948) is most conclusive since the condition cleared when the drug was stopped, only to recur when it was taken again. The prognosis of this type of nephrotic syndrome is good if the aetiology is recognized early in the course of the disease and administration of the noxious agent is stopped. Clinicians should carefully question all patients with a nephrotic syn- drome of unknown cause with regard to ingestion of drugs, since it is highly probable that many other medicaments may cause this condition.

(c) Following renal vein thrombosis and other causes of increased pressure in the renal veins. Thrombosis of the inferior vena cava involving the renal veins may lead to the nephrotic syndrome (Derow et al., 1939). This is relatively easy to diagnose if signs of inferior vena caval obstruction are present. In doubtful cases this may be confirmed by venography. In some cases, however, both renal veins may be thrombosed without involvement of the main caval trunk. In a recent case treated at Hammersmith Hospital, a boy, aged 7 , appeared to be a typical case of the nephrotic syndrome of unknown cause. He died of pneumococcal peritonitis, and at necropsy it was found that all the main tributaries of the renal veins were filled with organizing thrombus (Fig. I), the main renal vein trunks and the inferior vena cava not being involved. The thrombus clearly antedated the peritonitis and could well have dated from the onset of the disease. Such a case would be completely missed at necropsy if the renal veins and their tributaries within the kidney substance were not carefully examined.

Cardiac failure may very occasionally lead to proteinuria of sufficient degree to cause depression of plasma albumin and a nephrotic syndrome. Squire (1953) records a case of constrictive peri- 
carditis with many features typical of the nephrotic syndrome. The massive proteinuria and other nephrotic features cleared after pericardectomy.

(d) Cases secondary to acute glomerulonephritis. This is the rapidly progressive course of Ellis (1942). Such cases are easy to recognize if they follow an overt attack of acute nephritis, but difficult if secondary to a sub-clinical attack. They are likely to show haematuria and hypertension from the onset and death from uraemia occurs less than one year from the start of the illness. This rapidly progressive course seems to be not uncommon following acute nephritis associated with Henoch-Schonlein purpura (Harrison et al., 1954).

(e) Cases of unknown cause (Type 2 nephritis of Ellis, 1942; 'pure lipoid nephrosis' of Volhard and Fahr, I9I4). It may well be that this class does not form a uniform entity and as more causes of the nephrotic syndrome are discovered it will become a still smaller group. There is little doubt that this is a disease different from acute glomerulonephritis (Type I, Ellis). The course may be prolonged over many years unless death from intercurrent infection occurs. Many cases recover completely with disappearance of the oedema and albuminuria-I 5 per cent. of Ellis's series, 26 per cent. of the series of Barnett et al. (1952). This disease, like acute glomerulo-nephritis, is commonest in childhood but the exact age distribution is different. Type 2 nephritis occurs most frequently in the age group two to four years; Type $I$ nephritis in the age group five to nine years (Barnett et al., 1952). It is clear from this age distribution that Type 2 nephritis cannot follow Type I; no one has ever suggested that the reverse occurs. In addition, the two conditions have a different pathological picture. Type I nephritis shows acute glomerular inflammation in the acute stage followed by organization and fibrosis in the cases which become chronic. Type 2 nephritis shows a degenerative pathological picture with thickening of the basement membrane and hyalinization of the glomeruli. The combined clinical and pathological investigation of Davson and Platt (1949) gives further evidence that the conditions are distinct.

In doubtful cases special laboratory investigations may assist in the diagnosis. The inulin clearance has many advantages over the urea clearance in the assessment of glomerular function in the nephrotic syndrome (Bruck et al., 1954). The urea clearance is especially liable to error in the presence of oliguria. The level of blood urea tends to be variable in the nephrotic syndrome since a high protein diet is usually prescribed despite the notoriously capricious appetite of these patients. Reduction in the inulin clearance early in the course of the disease suggests that the diagnosis is not Type 2 nephritis. In Type $1 \stackrel{\mathbb{Q}}{\stackrel{2}{2}}$ nephritis the ratio of inulin to PAH clearance $c$. (filtration fraction) is depressed and this tends to $\overrightarrow{\vec{F}}$ persist if the condition passes into the nephrotic $\stackrel{?}{+}$ stage. This ratio is usually normal in Type 2 nephritis. Paper electrophoresis of plasma proteins may also be of value (Lagrue et al., 1954). In Type 2 nephritis the concentration of $\gamma_{-}$ globulin tends to be below normal. In Type I ڤ nephritis it is normal or high and is always in- $\vec{O}$ creased in amyloidosis or lupus erythematosus.

\section{Pyelo-Nephritis}

There is comparatively little controversy with regard to the classification and definition of 3 pyelo-nephritis, but we are still completely unable ${ }^{\omega}$ to explain the diverse clinical features of this $\omega$ disease. Acute pyelo-nephritis provides no diag- . nostic problem, being associated with a typical $\$$ clinical picture of loin pain, frequency of micturition and dysuria and always showing evidence of urinary infection and pyuria. Chronic pyelonephritis usually follows an incompletely treated acute attack and runs a prolonged course associated with exacerbations and remissions. Bacteriurio and pyuria are present in the exacerbations, but $\frac{\Phi}{-}$ the urine may be almost normal during the reo $\overrightarrow{0}$ missions of the disease. Some cases give ne of history of an acute attack and present with evidence of progressive renal failure. Tests of renal function can assist in the diagnosis of such cases since there is always evidence of greater loss of tubular than of glomerular function. In particular, loss of concentrating power usually precedes urea retention (Raaschou, 1943) and the ratio of inulin clearance to tubular maximal reabsorptive capacity for PAH $\left(\mathrm{C}_{1 n} / \mathrm{Tm}\right.$ PAH) is increased (Raaschou, 1948). The reverse applies in glomerulonephritis. There is also clear pathological $\frac{}{2}$ evidence (Staemmler and Dopheide, I930) that in chronic pyelo-nephritis, tubular damage precedes involvement of the glomeruli.

Pyelo-nephritis may or may not lead to secondary hypertension and this may develop at a time when renal function is perfectly normal. This is 은 especially well seen in cases of severe hypertension $\rightarrow$ due to unilateral pyelo-nephritis in whom excision of the affected kidney may lead to restoration of a $N$ normal blood pressure (Pickering and Heptinstall, $\sigma$ 1953). In other cases electrolyte abnormalities $\tilde{O}$ may dominate the clinical picture. Cases of so- N called 'salt-losing nephritis' presenting with a clinical picture similar to Addison's disease are 0 almost always examples of chronic pyelo-nephritis (Enticknap, 1952). Inability to acidify the urine $\stackrel{\text { ? }}{+}$ leads to cases of renal tubular acidosis usually 0 associated with hypercalcuria causing rickets and 
osteomalacia (Albright et al., 1946). Cases showing a disproportionate loss of potassium may present with attacks of hypokalaemic paralysis similar to those seen in familial periodic paralysis (Evans and Milne, 1954). Any combination of these several defects of electrolyte reabsorption may be seen in a single case and no convincing explanation has been offered to account for this differential effect of pyelo-nephritis on renal tubular function. Other cases of chronic pyelonephritis may present with insidious renal failure with or without hypertension. The reason why increase of blood pressure occurs in some cases of the disease and not in others is likewise a complete mystery.

The prognosis in pyelo-nephritis is dependent on whether the infection can be controlled, on the degree of renal impairment as measured by inulin or urea clearance and on the level of the blood pressure. In all varieties of nephritis, cases associated with severe hypertension show a more rapidly progressive course to terminal renal failure. Some cases of chronic pyelo-nephritis in whom the infection is well controlled and with a normal blood pressure may survive for many years even although there is moderately severe uraemia throughout.

\section{Chronic Nephritis}

All of the various types of renal disease discussed above may terminate in a stage of chronic nephritis with uraemia. Cases differ especially with regard to associated oedema or hypertension. Some cases of the nephrotic syndrome die of uraemia without losing their oedema, whilst others develop polyuria and a salt-losing rather than a salt-retaining state, with complete loss of oedema, before death from uraemia finally occurs. Uraemia without hypertension is an insidious and slowly progressive condition, the main evidence of the disease being normochromic anaemia and polyuria. When there is associated hypertension the clinical picture is much more acute and is dominated by symptoms and signs due to the hypertension alone, e.g. severe headaches, papilloedema and retinitis leading to loss of visual acuity and left ventricular failure. Other causes of renal failure have to be considered in the differential diagnosis, e.g. malignant essential hypertension, multiple myelomatosis and any condition causing chronic hypercalcuria. If the case is seen for the first time at this stage, diagnosis is usually dependent on a clear and accurate history. The single most important feature in assessment of the prognosis is the level of the diastolic blood pressure.

\section{Conclusion}

Classification of nephritis has now reached a reasonably rational state, but nomenclature is still not satisfactory. The division of primary glomerulo-nephritis into two separate types is clearly necessary, but indefinite retention of the terms ' Type I' and 'Type 2 ' is probably undesirable. These terms were chosen by Ellis (1942) as being non-committal with regard to aetiology. They have never been widely adopted by American and Continental clinicians who usually require an explanation before understanding them. In addition, these names are not in accordance with the general nomenclature of disease. Generally acceptable alternative names are required, however, before they can be discarded since they have the great advantage of covering the whole of the disease process from inception to resolution or death. Whilst the great majority of cases of primary glomerulonephritis can be placed accurately into one or the other group, there is the occasional case which is difficult to classify and which shows features of both. The irreverent have been tempted to term these cases ' Type one point five.'

\section{Acknowledgments}

Thanks are expressed to Professor J. McMichael and Dr. C. V. Harrison for advice, to Dr. C. E. Newman and Dr. C. L. Cope for permission to mention cases under their medical care and to Dr. C. V. Harrison for permission to reproduce the micro-photograph.

\section{REFERENCES}

'ALBRIGHT, F., BURNETT, C. H., PARSON, W., REIFENSTEIN, E. C. and ROOS, A. (1946), Medicine, 25, 399.

'BARNETT, H. L., FORMAN, C. W. and LAUSON, H. D. (1952), Adv. Paediat., 5, 53.

'BARNETT, H L., SIMONS, D. J. and WELLS, R. E. (1948), Amer. $\dot{f}$. Med., 4, 760 .

'BROWN, L. (1916), Brit. med. F., 2, 723.

'BRUCK, E., RAPOPORT, M. and RUBIN, M. I. (1954), $\mathfrak{f}$. clin. Invest., 33, 699.

'CHINARD, F. P., LAUSON, H. D., EDER, H. A., GREIF, R. L. and HILLER, A. (1954), $\dot{F}$. clin. Invest., 33, 621.

'DAUGHERTY, G. W. and BAGGENSTOSS, A. H. (1950) Arch. int. Med., 85, 900 .

'DAVSON, J. and PLATT, R. (1949), Quart. F. Med., (n.s.), 18, 149.

'DEROW, H. A., SCHLESINGER, M. J. and SAVITZ, H. A. (1939), Arch. int. Med., 63, 626.

${ }^{10}$ ELLIS, A. (1942), Lancet, i, 1 .

${ }^{1}$ ENTICKNAP, J. B. (1952), Lancet, ii, 458.

${ }^{12}$ EVANS, B. M., and MILNE, M. D. (1954), Brit. med. $\mathcal{F}$., in press. ${ }^{13}$ GALAN, E. (1949), Amer. F. Dis. Child., 77, 328.

"GITLIN, D. and JANEWAY, C. A. (r952), f. clin. Invest., 31, 223. ${ }^{15}$ HAMILTON, M., PICKERING, G. W., FRASER ROBERTS, J. A. and SÓWRYY, G. S. C. (1954), Clin. Sci., 13, 11 .

${ }^{\circ}$ HARRISON, C. V., MILNE, M. D., SEAL, R. M. E. and VENNING, G. R., to be published.

${ }^{17}$ IVERSEN, P. and BRUN, C. (195I), Amer. F. Med., II, 324.

${ }^{18} \mathrm{KARK}, \mathrm{R}$. M. and MUEHRAKE, R. C. (1954), Lancet, $i, 1047$

${ }^{1}$ KELLETT, C. E. (1952), Lancet, ii, $91 \mathrm{r}$.

${ }^{30}$ KEMPE, C. H., OLMSTED, R. W. and CURNEN, E. C. (195I), Pediatrics, 8, 393 .

${ }^{2}$ KIMMELSTIEL, P. and WILSON, C. (1936), Amer. F. Path., 12, 83.

${ }^{22}$ LAGRUE, G., MOZZICONACCI, P. and VIALATTE J. (1954), Ann. de Med., 55, 196.

References continued on page 654 
mucus secretion. I wonder whether this change cannot rather be related to the malnutrition from which he suffered. May not this be a hypoproteinaemic fatty change with fibrosis ? I think that the degree of bile duct proliferation is not excessive for that. The presence of mucous glands in the small bile ducts in the liver is not usually accepted, though of course the larger ducts secrete mucus. If there was a mucus blockage of larger ducts then I would expect more evidence of bile retention. There is a recent paper (Webster and Williams, 1953) describing five children dying with fibrocystic disease, and having cirrhosis of the liver; they all showed much the same picture as this patient but there was no evidence of abnormal mucus retention. And finally I would just like to ask if Dr. Bodian could give us any idea whether he thinks this is an abnormal mucus which is secreted, or whether there is an abnormality in the enzyme which destroys mucus? I think we discussed this with Dr. Elmes last time we conferenced a case of mucosis.

Professor Dible: Could I ask Dr. Bodian one question-can he relate the lack of sexual development to this condition?

Dr. Lennox: I guess that if Dr. Russell Fraser were here, he would say that it was simply the result of prolonged malnutrition-that you would get it in any long-standing chronic illness.

Dr. Cope: He had steatorrhoea surely.

Dr. Bodian: May I answer Professor Dible's question first? We have certainly seen this inhibition of sexual development in other conditions of chronic malnutrition, such as for instance Hirschsprung's disease, when the patient lived long enough. I don't think it is specific for this particular condition.

With regard to what Dr. Sherlock said, I am rather reluctant to take issue with such an eminent $\frac{2}{3}$ expert on liver pathology. I would have expected $\stackrel{\mathbb{Q}}{\varrho}$ that if this condition was related to chronic fattyc. change, it would be diffuse. Yet here it is $\overrightarrow{\vec{F}}$ demonstrably focal even in this old-standing case. $\stackrel{?}{+}$ It is a very focal condition and I think you can? find considerable areas of liver not showing the 음 change at all. Moreover, as I said initally, we have seen a similar change (though to a lesser $\stackrel{\mathbb{Q}}{\varrho}$ degree with regard to fibrosis) in new-born infants, and $I$ think that in itself would make $a \rightarrow$ nutritional factor unlikely. I am prepared $I_{-}^{\circ}$ think now to diagnose mucosis on the basis of $a_{\vec{\omega}}$ liver section alone.

Dr. Scadding: Before we go I must say a wordo about the lung changes. Relatively little has been 3 . said about them though they were the cause of this patient's first coming to this hospital and the immediate cause of his death. However, the discussion which we have had makes it abundantlyo clear that these changes are indeed a manifestation 0 of a much wider-spread underlying disorder. 으 Granted the hypothesis that there is this abnormalmucus secretion which is unduly tenacious, $\underset{\mathbb{D}}{\mathbb{2}}$

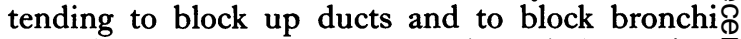
and difficult to expectorate, the whole pathe 3 genesis of the lung changes becomes clear. But@ I would like to close with the reflection that thos $\vec{\circ}$ relatively rare disease may perhaps emphasize farco us the extreme importance of the physico-chemiegi qualities of respiratory mucus (and that probabity applies to the mucus of the alimentary system also) in the causation of a number of much moreo common diseases; and in connection with theo

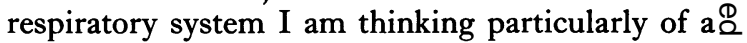
very common and disabling condition in this $\overrightarrow{\vec{O}}$ country, chronic bronchitis.

(The discussion in this case was considerably? curtailed by shortage of time.)

References continued from page 645-M. D. Milne, M.D., Ch.B., M.R.C.P.

${ }^{23}$ LANGE, K., GRAIG, F., OBERMAN, J., SLOBODY, L., OGUR, G. and LOCAS̉TO, F. (1951), Arch. int. Med., 88, 433.

${ }^{24}$ LYTTLE, J. D., SEEGAL, D., LOEB, E. N. and JOST, E. L. (1938), $\mathcal{f}$. clin. Invest., 17, 631 .

${ }^{25}$ MCCRAE, J. (1913), Tr. A. Amer. Physicians, 28, 194.

${ }^{20}$ MASUGI, M. (1934), Beitr. path. Anat., 92, 429.

${ }^{27}$ MUNK, F. (1913), Ztschr. f.klin. Med., 78, I.

${ }^{28}$ PICKERING, G. W. and HEPTINSTALL, R. H. (1953), Quart. F. Med., (n.s.), 22, I.

${ }^{20}$ RAASCHOU, F. (1943), Acta Med. Scandinav., 114, 414.

"RAASCHOU, F. (1945), Nord. Med., 25, 457.

"RAASCHOU, F. (1948), 'Studies of Chronic Pyelonephritis.' Copenhagen.

${ }^{32}$ RAMMELKAMP, C. H. and WEAVER, R. S. (1953), f. clin. Invest., 32, 345 .

${ }^{3}$ RAMMELKAMP, C. H., WEAVER, R. S. and DINGLE, J. H (1952), Tr. A. Amer. Physicians, 65, 168.

"REIMANN, H. A., SAHYOUN, P. F. and CHAGLASSIAN, H. T. (1954), Arch. int. Med., 93, 673.
${ }^{35}$ RUDEBECK, J. (1946), Acta Med. Scandinav., Supp. 173.

${ }^{3}{ }^{\circ}$ RYTAND, D. A. (1948), Amer. F. Med., 5, 548.

${ }^{3}$ SQUIRE, J. R. (1953), Brit. med. F., ii, 1389.

${ }^{38}$ STAEMMLER, M. and DOPHEIDE, W. (1930), Virchow's Arch. D f. path. Anat., 277, 713 .

${ }^{39}$ STICKNEY, J. M. and KEITH, N. M. (1940), Arch. int. Med., 66, 643 .

${ }^{4}$ SWANN, R. C. and MERRILL, J. P. (1953), Medicine, 32, 215.9

"THINGSTAD, R. (195I), Acta Med. Scandinav., 140, I.

"VALLERY-RADOT, P., MAURIC, G., WOLFROMM, R. and GUIOT, G. (1942), Bull. et Mem. Soc. Med. hop. Paris., 58, W 96.

"vOLHARD, F. and FAHR, T. (1914), Die Brightsche Nieren-2 krankenheit. Berlin.

"WEINSTEIN, L., BACHRACH, L. and BOYER, N. H. (1950), New Engl. F. Med., 242, 1002.

${ }^{45}$ WHITE, J. C. (1949), F. Amer. med. Ass., 139, 376.

${ }^{46}$ WILSON, V. K., THOMSON, M. L. and HOLZEL, A. (1952), Brit. med. $\mathscr{F}$., i, 358 . 